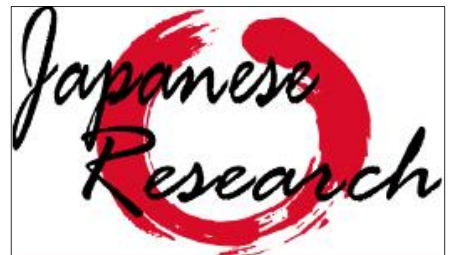

on Linguistics, Literature and Culture
Japanese Research on Linguistics, Literature, and Culture Vol. 1 No. 2 May 2019, Hal. 226-237

ISSN online: $2655-4836$

http://publikasi.dinus.ac.id/index.php/irllc/article/view/3009/1709 DOI : 10.33633/jr.v1i2.3009

Published by Universitas Dian Nuswantoro, Semarang

\title{
Paranoid Schizophrenia Suffered by the Lead Character on Kotoko Movie by Shinya Tsukamoto
}

\author{
Dwi Cahyo Arif Wibowo \\ Universitas Dian Nuswantoro \\ dwi.cahyo@gmail.com
}

Article History: Submitted date2019-09-24; Accepted date2019-10-07; Published date2019-10-17

\begin{abstract}
In this research, the writer explains about paranoid schizophrenia suffered by Kotoko. The purpose of this research is to analyze the characteristics and symptoms of paranoid schizophrenia. The data were taken from "КОТОКО" movie created by Shinya Tsukamoto (2011). The method used to analyzed the data is descriptive qualitative. Within modern social society, schizophrenia is a kind of social phenomenon problem. The symptom that usually appear in paranoid schizophrenia is delusions and hallutinations. The results show that becoming a single mother, post traumatic stress, over protective individua trigger the paranoid schizophrenia.
\end{abstract}

Keywords : paranoid schizophrenia, hallutination, delusion, traumatic

\begin{abstract}
Abstrak
Dalam penelitian ini, penulis menjelaskan skizofrenia paranoid yang diderita oleh Kotoko. Tujuan dari penelitian ini adalah untuk menganalisis karakteristik dan gejala skizofrenia paranoid. Data diambil dari film "КОTOKO" yang dibuat oleh Shinya Tsukamoto (2011). Metode yang digunakan untuk menganalisis data adalah deskriptif kualitatif. Dalam masyarakat sosial modern, skizofrenia adalah sejenis masalah fenomena sosial. Gejala yang biasanya muncul pada skizofrenia paranoid adalah delusi dan halusinasi. Hasil penelitian menunjukkan bahwa menjadi seorang ibu tunggal, stres pasca trauma, lebih dari pelindung individu memicu skizofrenia paranoid.
\end{abstract}

Kata kunci paranoid schizophrenia, halusinasi, delusi, traumatik 


\section{Pendahuluan}

Jepang merupakan salah satu negara maju di Asia yang memiliki kemajuan dan keberhasilan teknologi yang cukup diperhitungkan di dunia. Seiring perkembangan modernisasi yang cepat dan luas menjadikan pengaruh perubahan yang sangat besar dalam kehidupan orang jepang meliputi aspek ekonomi, politik, sosial, dan budaya. Dalam segi kebudayaan negara Jepang dikenal luas melalui produk budaya populernya, seperti anime, manga, J-pop dan dorama. Dari budaya populer tersebut kita secara tidak langsung dapat mempelajari dan mengetahui perilaku kehidupan orang Jepang.

Drama merupakan bagian dalam ragam karya sastra atau pentas yang terdiri dari dialog suguhan cerita dengan dasar berasal dari kehidupan. Menurut Wiyanto (2002:1-2) drama berarti perbuatan, tindakan. Berasal dari bahasa Yunani "draomai" yang berarti berbuat, berlaku, tindakan dan sebagainya. Drama adalah hidup yang dilukiskan dengan gerak.Konflik dari sifat manusia merupakan sumber pokok drama.

Menurut Mustopo (1989:23) dalam kesusastraan dikenal pula bentuk drama sebagai wujud fiksi karya prosais. Apabila drama digunakan sebagai sumber pengajaran ilmu budaya dasar, tentulah bukan suatu hal yang aneh, karena dalam batas-batas tertentu unsur-unsur drama, terutama jika drama dilihat sebagai karya sastra dapat disajikan lewat materi fiksi. Drama pada dasarnya dapat disikapi sebagai karya pentas dan karya sastra.

Film drama asal Jepang memiliki daya tarik tersendiri bagi pengemarnya. Banyak tema-tema menarik yang mengangkat permasalahan sosial dan fenomena-fenomena yang terjadi dalam masyarakat Jepang, konflik yang disuguhkan mulai dari percintaan, kekerasan, bullying (ijime) dan sebagainya. Melalui cerita dalam film penonton secara tidak langsung menghayati dan merasakan permasalahan kehidupan yang dialami oleh tokoh-tokoh yang difilmkan.

Salah satu bentuk fenomena dalam masyarakat Jepang saat ini adalah tingkat stress tekanan dalam kehidupan. Derasnya perubahan dan pengaruh pola hidup perkotaan membuat seseorang terkadang mengalami bentuk-bentuk banyak tekanan yang mengakibatkan depresi pada diri seseorang. Tidak stabilnya kondisi kejiwaaan seseorang mengakibatkan alur cara berpikir yang tidak lazim atau abnormal.

Film Kotoko adalah karya Shinya Tsukamoto yang dirilis pada tanggal 8 September 2011 dan merupakan Best Film award di festival Orizzonti. Dalam film dikisahkan Kotoko 
merupakan seorang single mother yang mengalami gangguan jiwa skizofrenia. sering mengalami kesulitan membedakan antara realitas dan imajinasi dalam dirinya. Bentuk gejala halusinasi dan delusi negatif yang sering timbul membuat rasa cemas, takut dan curiga akan semua orang di sekitarnya. Gejala-gejala tersebut sudah pasti bukan sematamata muncul begitu saja, melainkan ada sebab/pemicu yang terjadi, seperti kondisi kehidupan, trauma, ataupun permasalahan-permasalahan yang lain.

Kondisi tokok utama Kotoko dalam Film Kotoko yang mengalami skizofrenia paranoid dilihat dari pemicu dan gejala-gejala yang timbul, membuat penulis tertarik untuk meneliti secara lebih mendalam.

\subsection{Metode Penelitian}

Sumber Metode penelitian ini menggunakan metode yang bersifat kualitatif deskriptif. Penulis mempersiapkan data yang kemudian memanfaatkan teori-teori sebagai bahan pendukung, sebagai bahan untuk memperkuat pendapat yang dikemukakan oleh penulis. Tahapan penelitian ini meliputi, menonton film, membuat skrip, mengelompokkan data, dan kemudian menganalisisnya.

Dalam penelitian ini penulis menggunakan data primer berupa film Kotoko karya Shinya Tsukamoto yang dirilis pada tanggal 8 September 2011.

Teknik pengumpulan data meliputi : mentrasliterasi skrip film ke dalam terjemahan bahasa Indonesia untuk memahami isinya. Membaca sumber data secara berulang dan mendalam. Terakhir memilah data yang berkaitan dengan pokok permasalahan.

\section{Hasil dan Pembahasan}

\subsection{Unsur Intrinsik}

Plot

Alur atau plot cerita yang terdapat pada film Kotoko karya Shinya Tsumamoto, dapat dilihat pada diagram nucleus sebagai berikut:

a. Perkenalan:

Kotoko adalah seorang single mother yang memiliki seorang anak laki-laki dari hubungan di luar pernikahan.

“ところで私に子がいる、結婚したことがない、指輪は男わけ。” (part 1 menit 05.50-06.02) 
"Tokoro de watashi ni kodomo ga iru, kekkonshita koto ga nai, yubiwa ha otoko wake."

"Ngomong-omong saya mempunyai anak tanpa adanya pernikahan. Seorang anak laki-laki.

Kutipan di atas menunjukkan bahwa Kotoko merupakan seorang single mother yang tidak memiliki status kejelasan dalam perkawinannya. Dalam mengurus anaknya Kotoko memiliki sikap over protective, dirinya menganggap bahwa lingkungan dan orang-orang di sekitarnya membuat keduannya dalam ancaman. Hal ini dapat dilihat dari kutipan berikut :

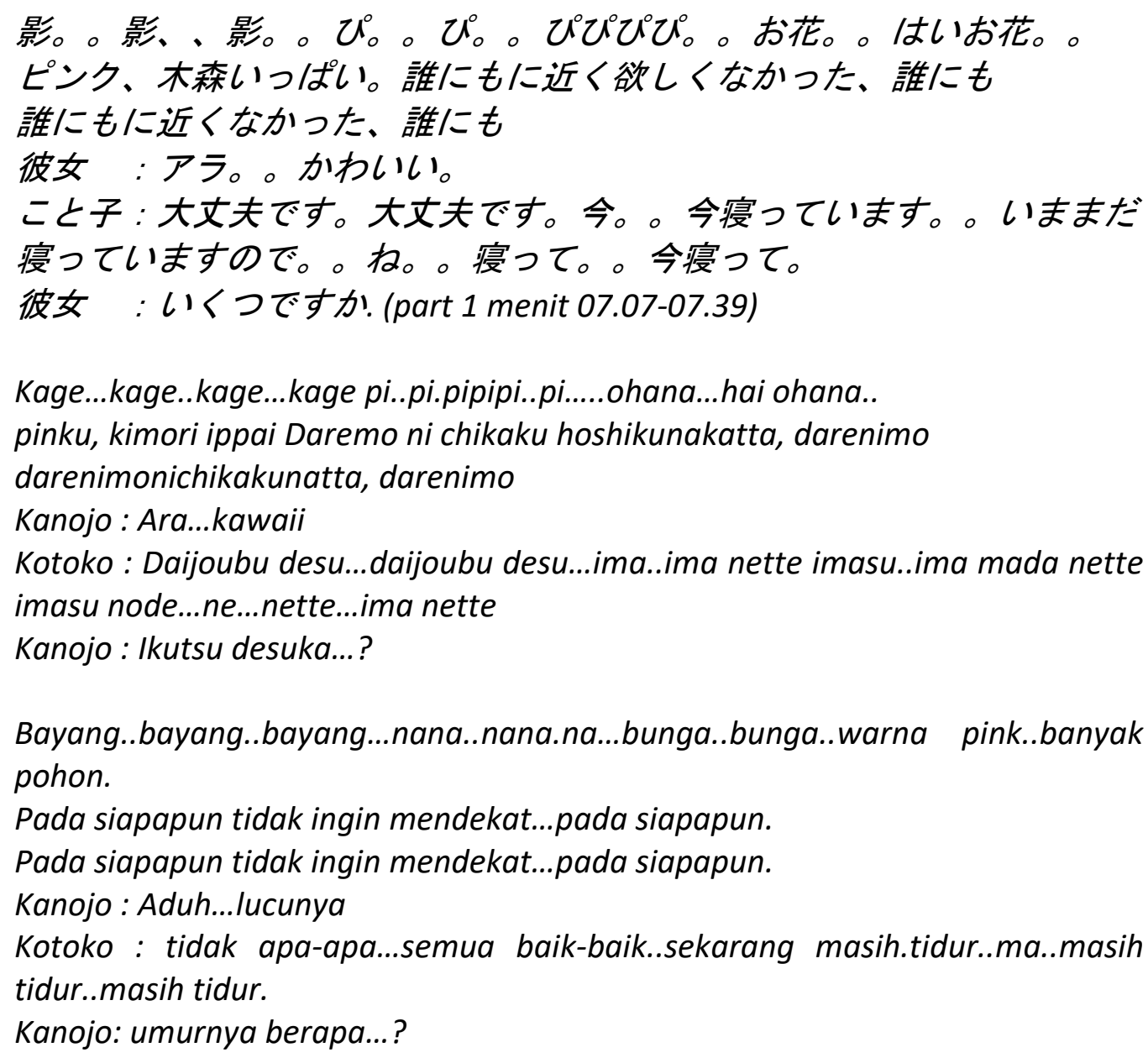

Dialog di atas menunjukkan sikap Kotoko ketika hendak berjalan-jalan bersama anaknya. Di suatu persimpangan jalan Kotoko bertemu seorang wanita yang mendekati dirinya kemudian menyapa dan mengatakan bahwa anaknya lucu, namun Kotoko seakanakan bersikap menghindari wanita yang ingin mendekati anaknya dengan berusaha berbohong bahwa anaknya tertidur. Alasan sebab-akibat bahwa Kotoko bersikap over protective adalah halusinasi yang sering muncul pada dirinya dan diikuti oleh gangguan 
delusi. Dirinya merasa cemas karena halusinasi yang dilihatnya sering terpecah menjadi dua seakan mengancam dirinya.

b. Permasalahan Muncul :

Kotoko mulai kehilangan kontrol dalam mengasuh anaknya. Dia merasa tidak tahu apa yang harus ia perbuat. Saat Kotoko memasak di dapur anaknya menangis.

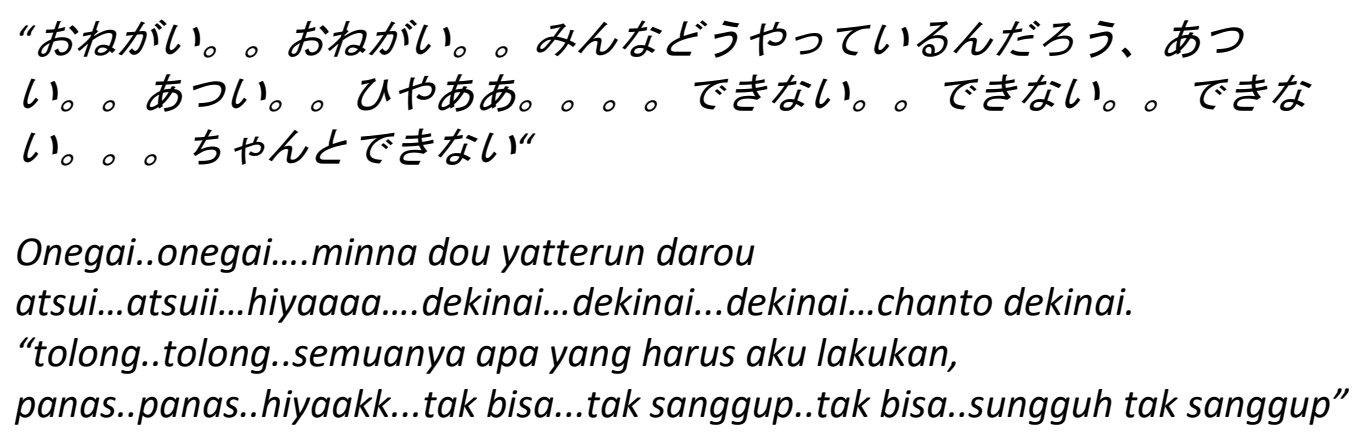

Kutipan dialog di atas menunjukkan Kotoko merasa tidak sanggup atas keadaan yang dihadapinya dia mengatakan (皆どうやっているんだろう) dia membutuhkan seseorang untuk diajak berbicara. Namun dirinya hanya seorang diri, sampai akhirnya untuk melampiaskan kekesalan dan stress dalam dirinya, Kotoko membanting penggorengan.

c. Permasalahan memuncak:

Sosok Tanaka yang menjadi pendamping hidup menjadikan Kotoko perlahan-lahan hidup dengan keceriaan. Namun hal demikian tidak berlangsung lama, Kotoko merasa bahwa sosok Tanaka perlahan-lahan menghilang dalam kehidupannya. Dengan menghilangnya seorang sosok Tanaka, Kotoko kembali mengalami halusinasi-halusinasi ketakutan yang diikuti oleh delusi-delusi tertentu.

d. Klimaks:

Kotoko mengalami halusinasi yang hebat saat pulang dari berbelanja, anaknya yang mengijak sekitar umur 3 tahun berlari-lari mendahului langkah Kotoko.Namun karena membawa barang belanjaan dia merasa kesulitan mengejar anaknya, anaknya menaiki tangga dan Kotoko mengikuti tapi setelah sampai diatas rooftop dia tidak menemukan anaknya.Lalu terdengar suara mobil menabrak sesuatu, Kotoko melihat dari atas rooftop bahwa anaknya telah tertabrak. Kotoko mengalami shock tapi seketika didepan matanya bahwa anaknya berdiri dan baik-baik saja. 
Halusinasi yang lain adalah setelah melihat televisi yang menayangkan adegan perang. Dia terbayang-bayang suara tembakan sehingga membuat dirinya seakan-akan masuk kedalam situasi penyandraan dalam perang, didalam halusinasinya dia melihat sosok prajurit berseragam yang hendak menyakiti anaknya. Kotoko memukul-mukul prajurit tersebut karena ingin menyelamatkan anaknya. Namun Kotoko tidak berdaya, dia seolah dipukul senapan dan tergeletak menyaksikan anaknya tertembak senapan.

e. Anti klimaks:

Setelah mengalami halusinasi dan delusi yang hebat Kotoko tersadar bahwa dirinya berada di lain tempat yang dipenuhi dengan hiasan warna-warni di dinding kardus. Diiringi suara lonceng dan desir angin dia menatap sekelilingnya, seketika itu dia juga merasa dalam keheningan.

f. Penyelesaian:

Kotoko mengalami Skizofrenia dan berada di dalam sebuah ruangan yang serba putih dapat dilihat dari kutipan di bawah ini:

“ましるま白い世界、聞いたらー日に一回なら、たばこを吸うときは外 に出らるというのが分かった、はい、すいます、タバコ、すいます、絶 対私希望します。“

"Mashiru ,mashiroi sekai,Kiitara ichinichini ikkai nara, tabako o suu toki wa sotoni derareru to iu no ga wakkata.Haik suimasu, tabako, suimasu, zettai watashi kiboushimasu."

"putih, dunia putih, bisa dikatakan kalau dalam sehari satu kali, di saat ingin merokok dapat keluar, ya menghisap, rokok, menghisap, saya harus berharap."

Dialog kutipan di atas menunjukkan bahwa Kotoko mengatakan hal-hal di sekitar yang dia lihat semuanya serba putih dan tidak lain adalah tempat di mana Kotoko berada sekarang, yaitu sebuah ruangan rumah sakit. Di dalam ruangan itu Kotoko didampingi oleh seorang perawat pria yang mengantar Kotoko pergi ke luar ruangan di saat dia ingin merokok.

Tokoh dan Penokohan 
Pada film Kotoko karya Shinya tsukamoto ini terdapat tiga tokoh yaitu Kotoko, Tanaka, dan Daijirou. Karakteristik dari ketiga tokoh tersebut dapat dijelaskan secara lengkapnya sebagai berikut:

1. (Kotoko) seorang wanita single mother yang memiliki kepribadian kehidupannya menutup diri dari lingkungan di sekitarnya.

2. (Tanaka) seorang pria yang berprofesi sebagai novelis yang berkepribadian empati (peduli, kasih sayang, perhatian) yang tinggi,

3. (Daijirou) seorang anak yang tidak mendapatkan asuhan seutuhnya dari orang tua kandungnya. Kepribadian yang menonjol adalah rasa peduli kepada ibunya meskipun mengalami gangguan jiwa.Dia tidak menghiraukan dan masih berkomunikasi mengenai kegiatan aktivitasnya.

\subsection{Faktor-faktor Pemicu Skizofrenia pada tokoh Kotoko karya Shinya Tsukamoto}

\section{Status dirinya sebagai seorang single mother yang memiliki kelainan dalam penglihatan.}

こと子：二つ見える。どっちが本当か分からなくなる

王さん：ぽおお。。ひいい。。ぽおお。。ひ。。ぽ。ひ涪。ぽこと 子：被弾すると命にかかわるから、毎日真剣使用子です。

(part 1 bagian menit 02.29 03.30)

Kotoko : Futatsu mieru. Dochi ga hontoka wakaranaku naru Ousan: Pooo..piii..pooo....pi po pi po

Kotoko : Hidansuru to inochini kakawaru kara, mainichi shinkenshiyouko desu.

Kotoko : terlihat menjadi dua. Mana yang sesungguhnya saya tidak tahu Otousan : tilut..tilut..tilutt....

Kotoko : karena hidup dalam tekanan, seakan-akan setiap hari dibayangi halhal yang mengancam jiwa

Kutipan di atas menunjukkan Kotoko penglihatannya terpecah menjadi dua, kondisi demikian membuat Kotoko sulit membedakan mana yang realita dan nonrealita. penglihatan yang dialami Kotoko sangat menggangu dirinya, karena hal yang dilihatnya seolah-olah akan mengancam anak dan dirinya, sehingga rasa cemas, takut, gelisah dan khawatir menghantui di pikiran Kotoko. 
Kotoko tidak memiliki tempat mencurahkan permasalahan.

Di suatu ketika Kotoko memasak didapur dengan mengendong anaknya yang sedang menangis. Dia merasa kesulitan untuk menenangkan anaknya sehingga makanan yang dia tuangkan kedalam piring tumpah lalu mengenai dirinya lalu dia merintih kepanasan dan berteriak

“おねがい。。おねがい。。みんなどうやっているんだろう、あつ い。。あつい。。ひやああ。。。。できない。。できない。。できな い。。。ちやんとできない゙

(bagian menit 13.02 14.02)

Onegai..onegai....minna dou yatterun darou

atsui...atsuii...hiyaaaa....dekinai...dekinai...dekinai...chanto dekinai.

"tolong..tolong..semuanya apa yang harus aku lakukan, panas..panas..hiyaakk...tak bisa...tak sanggup..tak bisa..sungguh tak sanggup"

Kutipan dialog di atas menunjukkan Kotoko merasa tidak sanggup atas keadaan yang dihadapinya dia mengatakan （皆どうやっているんだろう） dia membutuhkan seseorang untuk diajak berbicara. Namun dirinya hanya seorang diri, sampai akhirnya untuk melampiaskan kekesalan dan stress dalam dirinya, Kotoko membanting penggorengan.

\section{Trauma dekat dengan seorang lelaki}

Suatu ketika Kotoko bertemu seorang pemuda yang ingin mendekatinya di jalan. Pemuda tersebut mengajaknya makan di sebuah restaurant, Kotoko tidak menolak namun dia merasa saat apa saja yang diobrolkan kepadanya adalah omong kosong belaka. Hal ini dapat dilihat dari ekspresi Kotoko saat mendengarkan pemuda tersebut berbicara. Kotoko dalam hatinya dengan nada kurang lelah berkata :

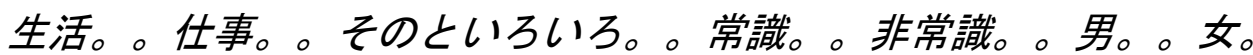
(bagian menit 17.18 17.02)

Seikatsu..shigoto..sono to iro iro...joushiki..hijoushiki...otoko..onna.

Kehidupan..pekerjaan...dan lain-lain..masuk akal..tidak masuk akal..lakilaki..perempuan. 
Perkataan dialog di atas menunjukkan bahwa Kotoko merasa lelah dengan apa yang terjadi dalam kehidupannya, pekerjaan maupun masalah hubungan dengan lawan jenisnya. Kotoko pun menusukan garpu ke tangan pemuda tersebut merasa karena hal-hal yang dikatakan baginya adalah omong kosong belaka.

\subsection{GEJALA SKIZOFRENIA PADA TOKOH КОTOKO}

\section{Gejala Primer}

a. Afek/Respon emosional

Afek pada Kotoko terlihat di saat setelah Kotoko kembali dari kampung halamannya untuk menengok anaknya Daijirou dan hendak bercerita kepada kakaknya bahwa dia telah menemukan pendamping hidup yang baru, Tanaka yang mengajaknya pulang ke kampung halaman berniat untuk melamar dan meyakinkan cintanya kepada Kotoko bahwa dia bersungguh-sungguh mencintai Kotoko dan Daijirou.

こと子：ごめんやりすぎた。

田中：大丈夫だよう。。全然大丈夫

(part3 menit04.45-05.05)

Kotoko : Gomen yarisugita

Tanaka : Daijoubu dayo..zenzen daijoubu

Kotoko : Maaf ya ...berlebihan

Tanaka : Tidak apa...sama sekali tidak apa-apa

Kutipan tersebut merupakan perkataan Kotoko kepada Tanaka. Dengan perasaan senang dan memandang cincin yang diberikan oleh Tanaka, Kotoko meminta maaf kepada Tanaka yang belumuran darah dan terluka memar di sekitar wajahnya akibat prilaku Kotoko. Tanaka memaklumi prilaku Kotoko sehingga dia merespon bahwa dia baik-baik saja. Kondisi demikian menunjukkan bahwa hilangnya respon terhadap peristiwa yang tidak menyenangkan oleh Kotoko karena Kotoko tersenyum sambil bernyanyi walaupun melihat Tanaka dalam keadaan demikian. Kotoko mengalami afek datar atau tidak sesuai yaitu kondisi dimana peristiwa menyenangkan dan menyedihkan menjadi sama atau sejajar. 


\section{Gejala Sekunder}

\section{Delusi}

Indikasi skizofrenia paranoid pada Kotoko ditandai dengan gejala-gejala delusi persekusi, yakni di saat bermain bersama anaknya dia mengalami bahwa ada orang tertentu sedang mengancam atau berencana membahayakan dirinya.

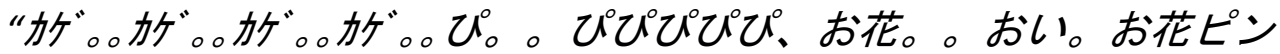
ク、誰にもにちかくほしゅくなかった、だれにも。”

( part 1 bagian menit 07.05 07.23)

"kage..kage...kage..kage..pi..pipipipi, ohana..oi..ohana pinku,darenimo ni chiikaku hoshikunakatta, darenimo."

Saya dalam keadaan yang tidak percaya akan diri sendiri...dengan tangan kurus ini ..bicara dengan tangan ini..berbicara...Daijirou akan lepas..jatuhh..kalau terlepas..jatuh Bayang..bayang..bayang...nana..nana.na...bunga..bunga..warna pink..banyak pohon. Pada siapapun tidak ingin mendekat...pada siapapun.
}

Penggalan dialog di atas menunjukkan Kotoko tidak ingin dekat siapapun. Sikapnya yang menarik diri dari lingkungan sosial akibat rasa cemas, takut dan khawatir yang menghantui, Kotoko menganggap bahwa orang disekitarnya akan mengancam anak dan dirinya.

\section{Halusinasi}

\section{A. Halusinasi Visual (penglihatan)}

Halusinasi disaat menjaga Toko, Kotoko melihat seorang lelaki paruh baya memilih mainan dengan anaknya. Kotoko melihat lelaki paruh baya yang sama di sudut lain.

\section{こと子：二つ見える。どっちが本当か分からなくなる}

王さん：ぽおお。。ひいい。。ぽおお。。ぴ。ぽ。。ぴ。ぼこと 子：被弾すると命にかかわるから、毎日真剣使用子です。

(part 1 bagian menit 02.29 03.30)

Kotoko : Futatsu mieru. Dochi ga hontoka wakaranaku naru Ousan: Pooo..piii..pooo....pi po pi po Kotoko : Hidansuru to inochini kakawaru kara, mainichi shinkenshiyouko desu.

Kotoko : terlihat menjadi dua. Mana yang sesungguhnya saya tidak tahu 
Otousan : tilut..tilut..tilutt....

Kutipan di atas menunjukkan Kotoko terpecah menjadi dua, kondisi demikian membuat Kotoko sulit membedakan mana yang realita dan non realita.

\section{B. Halusinasi Akustik ( Pendengaran)}

Kotoko mengalami kesulitan untuk menenangkan anaknya yang sedang menangis, lalu dirinya pergi ke atas rooftop mencari suasana yang lebih luas. Saat berada di lantai atap bangunan (rooftop) sambil mengendong anaknya. Muncul hasutan-hasutan.

こんなに私を信じきって、私のこんなに細いよ手た折にして。。手を離

したら。。手をちよつと離したら。。。大二郎はお子散る。。お子散 る。。怒ったら。。怒ったら

konna ni watashi wo shinji kitte, watashino konna ni hosoiyo te taori ni shite....te o hanashitara...te o chotto hanashitara...daijirou wa okochiru...okochiru....okottara...okottara

Saya dalam keadaan yang tidak percaya akan diri sendiri...dengan tangan kurus ini ..bicara dengan tangan ini..berbicara...Daijirou akan lepas..jatuhh..kalau terlepas..jatuh.

Hasutan-hasutan yang didengar oleh Kotoko membuat Kotoko melepas anak yang digendongnya dari atap atas. Halusinasi akustik atau halusinasi pada pendengaran. Ini dialami Kotoko beberapa kali, sesaat bersama sang anak bisikan-bisikan dalam lubuk hati dan pikirannya berupa bahaya "abunai", jatuh "ochiru" yaitu bisikan untuk mengakhiri hidup anaknya dengan menjatuhkan dari atas bangunan.

\section{Simpulan}

Hasil analisis film Kotoko karya Shinya Tsukamoto menunjukkan bahwa Kotoko mengalami Skizofrenia Paranoid. Berdasarkan gejala-gejala yang ditemukan lebih banyak muncul halusinasi dan delusi yang terlihat. Gejala yang timbul saling berkaitan dengan perjalanan kehidupan Kotoko, secara garis besar dapat disimpulkan bahwa faktor-faktor yang menyebabkan Kotoko mengalami gangguan skizofrenia paranoid adalah (1) Kotoko seorang single mother yang memiliki kelainan dalam penglihatannya, (2) Persepsi negatif yang sering muncul terhadap gangguan yang dialaminya, (3) Kehidupan menarik diri dan tidak adanya teman membuat Kotoko tidak dapat berbagi sehingga masalah yang 
dialaminya terpendam, (4) Trauma terhadap lawan jenis membuat Kotoko menjaga jarak, curiga dengan setiap lelaki yang mendekati.

\section{Daftar Pustaka}

Wiyatmi (2011). Psikologi Sastra Teori dan Aplikasi, Yogyakarta : Kanwa Publiser.

APA. DSM IV-TR. (2000). Diagnostic and Statistical Manual of Mental Disorder Fourth Edition Text Revision. Washington DC: Published by American Psychiatric Association.

Durand, V.Mark dan David H. Barlow (2007). Intisari Psikologi Abnormal edisi 4. Yogyakarta : PUSTAKA PELAJAR

Davidson, C., Gerald, \& Neale, M. John. (2006). Psikologi Abnormal. Jakarta: PT. Raja Grafindo Persada.

Noviana, F. (2013). Gangguan kejiwaan tokoh utama novel Haguruma karya Akutagawa Ryuunosuke. IZUMI, 2(2)

Nevid, Jefrey S, Spencer A. Rathus, Beverly Greene (2003). Psikologi Abnormal edisi 5, Jakarta : Penerbit Erlangga.

ejournal.umm.ac.id/index.php/jib/.../1347_umm_scientific_journal.pdf (diakses tanggal 8 Februari 2015)

http://lib.ui.ac.id/file?file=digital/126477-TESIS0535\%20Car\%20N08p-

Pengaruh\%20penerapan-Literatur.pdf (diakses tanggal 8 Februari 2015)

http://repository.usu.ac.id/bitstream/handle/123456789/24963/Chapter\%20II.pdf;jsessioni $\mathrm{d}=\mathrm{FA675EA71E4E8CE68E6CD35283A085FE}$ ?sequence $=4$ (diakses tanggal 15 Februari 2015)

https://psikologiabnormal.wikispaces.com/Schizophrenia+Paranoid?responseToken $=04790$ 4aee5c9d6ca53760e363c92015ce (diakses tanggal 20 Februari 2015) 